This is the author's final, peer-reviewed manuscript as accepted for publication. The publisher-formatted version may be available through the publisher's web site or your institution's library.

\title{
Verbal redundancy aids memory for filmed entertainment dialogue
}

Michael P. Hinkin, Richard Jackson Harris, Andrew T. Miranda

\section{How to cite this manuscript}

If you make reference to this version of the manuscript, use the following information:

Hinkin, M. P., Harris, R. J., \& Miranda, A. T. (2014). Verbal redundancy aids memory for filmed entertainment dialogue. Retrieved from http://krex.ksu.edu

\section{Published Version Information}

Citation: Hinkin, M. P., Harris, R. J., \& Miranda, A. T. (2014). Verbal redundancy aids memory for filmed entertainment dialogue. Journal of Psychology: Interdisciplinary and Applied, 148(2), 161-176.

Copyright: Copyright (C) 2014 Taylor \& Francis Group, LLC

Digital Object Identifier (DOI): doi:10.1080/00223980.2013.767774

Publisher's Link:

http://www.tandfonline.com/doi/abs/10.1080/00223980.2013.767774\#.UzSYsKhdXL8

This item was retrieved from the K-State Research Exchange (K-REx), the institutional repository of Kansas State University. K-REx is available at http://krex.ksu.edu 
In Press, Journal of Psychology: Interdisciplinary and Applied, 2013

Verbal Redundancy Aids Memory for Filmed Entertainment Dialogue

Michael P. Hinkin, Washburn University

Richard Jackson Harris, Kansas State University

and

Andrew T. Miranda, Wichita State University

Address correspondence to Richard J. Harris, Department of Psychology, Kansas State University, 492 Bluemont Hall, 1100 Mid-Campus Drive, Manhattan KS 66506-5302 USA;

rjharris@ksu.edu, 785-532-0610 


\begin{abstract}
Three studies investigated the effects of presentation modality and redundancy of verbal content on recognition memory for entertainment film dialogue. U.S. Participants watched two brief movie clips and afterward answered multiple-choice questions about information from the dialogue. Experiment 1 compared recognition memory for spoken dialogue in the native language (English) with subtitles in English, French, or no subtitles. Experiment 2 compared memory for material in English subtitles with spoken dialogue in either English, French or no sound. Experiment 3 examined three control conditions with no spoken or captioned material in the native language. All participants watched the same video clips and answered the same questions. Performance was consistently good whenever English dialogue appeared in either the subtitles or sound, and best of all when it appeared in both, supporting the facilitation of verbal redundancy. Performance was also better when English was only in the subtitles than when it was only spoken. Unexpectedly, sound or subtitles in an unfamiliar language (French) modestly improved performance, as long as there was also a familiar channel. Results extend multimedia research on verbal redundancy for expository material to verbal information in entertainment media.
\end{abstract}

Keywords: film entertainment, memory for film, subtitles, verbal redundancy,

Header: Memory for Subtitles and Dialogue 
Verbal Redundancy Aids Memory for Filmed Entertainment Dialogue

In many countries of the world much of the movie and television content is imported and routinely uses interlingual subtitles, with the spoken sound in one language and the written subtitles in another (Schilperoord, de Groot, \& van Son, 2005). Subtitling is also increasingly used within a single language (intralingual subtitling), as closed captioning for the hearingimpaired (de Linde \& Kay, 1999). Subtitles clearly are critical for viewers who cannot comprehend the speech, due to hearing loss or the sound being in a language unknown to them, although their effects on others who do not need them is not clear.

Subtitled film simultaneously conveys information in three channels: the pictorial content, the spoken dialogue, and the written subtitles (Dias-Cintas \& Remael, 2007; d'Ydewalle $\&$ de Bruycker, 2007; Pavlovic, 2004; Perego, et al., 2010). Subtitling in film and TV has a standard presentation time of six seconds, with a two-line subtitle with a maximum of 40 characters and spaces per line presented for 6 seconds (d'Ydewalle, Van Rensbergen \& Pollet, 1987; Ivarsson \& Carroll, 1998). Previous cognitive research on subtitles has particularly studied the influence of subtitles on directing attention (e.g., d'Ydewalle \& de Bruycker, 2007; Perego, del Missier, Porta, \& Mosconi, 2010), aiding foreign language acquisition (e.g., d'Ydewalle \& Van de Poel, 1999; Kuppens, 2010; van Lommel, Laenen, \& d'Ydewalle, 2006), and promoting literacy (Kothari, 1998, 2000; Kothari, Pandey, \& Chudgar, 2005). The current studies extended earlier research by testing recognition memory for entertainment film dialogue presented in various conditions of subtitles and sound.

People may have a strong, perhaps automatic, inclination to read verbal information. If this is the case, it may be that this time and effort taken to attempt to read words in an unfamiliar 
foreign language could potentially distract from attending to and allocating precious cognitive resources to comprehending oral information in the spoken dialogue. This seemingly automatic reading response (de Bruycker \& d'Ydewalle, 2003; d'Y dewalle \& de Bruycker, 2007; d'Ydewalle, et al., 1991; Perego, et al., 2010) may be seen as a sort of Stroop (1935) effect. If observers automatically attempt to read subtitles, even if unsuccessfully, attention may be drawn away from processing the native language sound and/or the pictorial content. Martin, Wogalter, and Forland (1988) found that any background sounds, including even an unfamiliar language being spoken, impaired performance on a concurrent reading comprehension task. They concluded that disruption of reading comprehension occurs when attention is captured even by irrelevant speech, although such disruption increased as background stimuli become more similar to the target reading material. It is possible, though as yet largely untested, that unneeded written subtitles might be a similar distraction.

Although the slightly more concise nature of subtitles relatively to speech suggests they might be an efficient way to quickly convey information (Perego, et al., 2010), subtitles also have some disadvantages relative to the speech (Koolstra, Peeters, \& Spinhof, 2002). For example, they typically involve some condensation or abridgement of the spoken text, which may result in some loss of information and some very minor inconsistencies between dialogue and subtitles. Indeed, Schilperoord, de Groot and van Son (2005) found that only $42 \%$ of coherence relations in a script fully survived subtitling, although most changes were minor. Redundancy becomes an issue when the viewer is familiar with both the language of the speech and that of the subtitles, which may thus be semantically redundant but not quite identical. Sometimes the subtitle may not even be a literal translation; when direct literal translations are not available, a subtitle translator must use a paraphrase. 
Another problem with adapting spoken dialogue to subtitles is the different length of time to comprehend speech versus the corresponding subtitles; listening to the spoken dialogue often requires longer real time than reading the subtitled material. Reading subtitles is different from typical reading in that the available reading time is limited, the subtitles appear only in a particular area of the screen, and visual events are happening concurrently on the screen (DiazCintas \& Remael, 2007). Subtitles must necessarily occlude part of the picture (Kalyuga, Chandler, \& Sweller, 1999; Koolstra et al., 2002). Although in most cases critical visual content is not substantially obscured by the subtitles, sometimes important visual information might be partially masked. However, this occlusion is probably minimal, given that eye movements tend to follow the face of the speaking character, who is usually positioned toward the center of the screen (Germeys \& d'Ydewalle, 2007).

There has been some memory research for multimedia presentations, primarily studying recall of pictorial and verbal expository material (Lang, 1995; Mayer, 1997, 2005, 2009; Rummer, Schweppe, Furstenberg, Scheiter, \& Zindler, 2011; Rummer, Schweppe, Furstenberg, Seufert, \& Brunken, 2010; Sweller, 2005). For example, Mayer and Moreno (1998) and Moreno and Mayer (2002) presented a pictorial representation explaining the formation of lightning with either accompanying written text or oral narration. Participants receiving the simultaneous congruent pictorial representation + oral narration performed better than the picture + written text condition on a memory test, a matching test, and a transfer test applying the material to solve new problems associated with lightning formation. A condition where words appeared both auditorily in the spoken dialogue and visually in the subtitles showed better performance than an auditory-only condition, as long as there was no other concurrent but potentially incongruent 
visual material. These results supported the idea that congruent inputs in different modalities enhance comprehension by allowing the observer to parallel process efficiently.

In spite of this evidence that simultaneous presentation of congruent verbal and pictorial information is a highly effective way to transmit information, it is also clear that there are processing limits which may be reached or exceeded with too much incongruent or unrelated information in simultaneous channels, as seen in the complex cluttered formats of some cable news channels (Bergen, Grimes, \& Potter, 2005) Another concern is that redundant or incomprehensible information in multiple channels is not only no help in comprehension but in fact is a distraction that interferes with learning. For example, Lavaur and Bairstow (2011) found that subtitles, either in one's own language or a foreign language, interfered with comprehension of the film North by Northwest, relative to a control condition with no subtitles. Other research on multimedia learning with a variety of materials has sometimes failed to replicate the earlier findings showing facilitation effect of redundancy (e.g., Lindow, Fuchs, Furstenberg, Kleber, Schweppe, \& Rummer, 2010; Schuler, Scheiter \& Schmidt-Weigand, 2010). Thus, the state of the field in regard to multimedia learning is consequently far from clear.

Although the multimedia research is instructive, it does not necessarily generalize to entertainment media. Many previous studies used expository prose like the formation of lightning, procedural learning like how a bicycle pump works, or dynamic didactic film stimuli with or without subtitles, while others used rapid visual presentation of sentences and abstract visual forms. The present studies examined memory for information from spoken and subtitled dialogue in filmed entertainment media. Viewers might follow the characters and plot in a film 
very differently than they would when learning factual exposition or procedural knowledge. With a few exceptions like Lavaur and Bairstow (2011), little previous subtitling research has examined entertainment media.

\section{Current Studies}

Given that largely the same information in film may occur in the subtitles, the dialogue, or both, two general conceptual questions arise. First of all, which of those channels is the better communicator of information? Second, if congruent information appears in both channels, does that verbal redundancy enhance comprehension and memory (two verbal channels in different modalities working together in parallel with the pictorial content), or does it detract from comprehension, leading to a tradeoff between pictorial and text processing (two verbal channels competing for attention and potentially distracting from the pictorial content)?

Building on previous work, the present studies extended the multimedia research on expository and procedural prose to filmed entertainment media, investigating the effects of subtitling on memory for dialogue from popular movies by systematically varying the language in the spoken dialogue and the subtitles. Two general research questions were examined: First, is recognition memory better for content when it occurs in the spoken dialogue, the subtitles, or both? Secondly, do extraneous foreign language subtitles or sound affect recognition memory for movie content when one's native language is in the subtitles or in the sound?

The present studies measured recognition memory, rather than comprehension directly. Although most people do not typically watch entertainment media for the explicit purpose of remembering the content at a later time, memory is nonetheless clearly a part of the enjoyment 
experience of film (Harris, Cady, \& Tran, 2006). If one cannot comprehend a film well enough to form memory representations of its content, it is not a very enjoyable experience. After watching movies, people often discuss them with friends and even quote movie dialogue in conversation (Harris, Werth, Bures, \& Bartel, 2008). Thus, studying memory for the content of entertainment films is less lacking in ecological validity than it might first appear. Four-option multiple-choice questions assessed the content communicated in both the subtitles and spoken dialogue; the exact wording in either channel was not of particular interest, given that, when people recall and discuss a movie they have seen, it is the semantic content, not the exact words, which is typically remembered.

The present research contained three studies, each comparing three different subtitlesound presentation formats and each addressing a different research question:

- Experiment 1: How do different subtitles enhance or interfere with recognition memory for spoken movie dialogue in one's native language?

- Experiment 2: How do different language in the spoken dialogue enhance or interfere with recognition memory for content in subtitles in one's native language?

- Experiment 3: What content do viewers remember from the picture alone and how do incomprehensible subtitles or sound affect that?

\section{Experiment 1: English Sound with Various Subtitles}

In this study, participants watched two ten-minute movie clips, with presentation format varied across conditions in terms of the dialogue in the subtitles. Although the spoken dialogue 
was always in English, subtitles varied across three presentation formats (English, French, or none).

\section{Hypotheses}

- H1: Consistent with Moreno and Mayer's research demonstrating facilitative effects of verbal redundancy, English Subtitles were predicted to lead to better memory than would French Subtitles or No Subtitles.

- H2: If French Subtitles are a distraction, as found by Lavaur and Bairstow (2011), then memory should be worse than in the No Subtitles condition.

Method

Participants. 150 undergraduate students enrolled in General Psychology classes at a large Midwestern U.S. university participated as part of their course requirement. All were native English speakers and were randomly assigned to one of three experimental conditions: English sound with English subtitles (English Subtitles), English sound with French subtitles (French Subtitles), or English sound with no subtitles (No Subtitles), with 50 participants in each group. French was selected as the foreign language because is not a common language encountered in the Midwestern United States, making it less likely that participants would possess extensive exposure, and also because of the availability on DVD of English-language movies with French subtitles and sound. The participants seeing the French subtitles were screened to ensure that they had had no prior formal study or experience with the French language. 
Materials and Apparatus. The two ten-minute film clips included 1) a talky courtroom scene with little action from the 1992 drama A Few Good Men and 2) a compilation of three contiguous comic action scenes from the 1989 comedy See No Evil, Hear No Evil. These were selected to include a variety of types of scenes, in order to allow some minimal level of generalization across movies and genres. Although the subtitles were not verbatim reproductions of the spoken dialogue (subtitles almost never are), they were examined to ensure that they were very close in meaning and not incongruent.

The paper-and-pencil materials consisted of a 33-item 4-choice multiple-choice recognition memory test for the information in A Few Good Men and a 35-item test for material in See No Evil, Hear No Evil. Of these 68 questions, 41 tested material which occurred both in the spoken dialogue and subtitles, after pilot testing ensured they were of moderate difficulty. All questions tested memory for content which was communicated completely in both the subtitles and the spoken dialogue, although not necessarily in exactly the same wording; verbatim memory was not assessed. The tests also contained 27 filler questions about information appearing only in the pictorial content of the film, material not mentioned in the dialogue. No question assessed material appearing only in the subtitles or sound but not the other, nor was material in facial expressions, voice inflections, sound effects, or background noise tested. Questions appeared in the same consistent order for all participants, with critical and filler items interspersed. A final demographic questionnaire asked about prior viewings of the movies and experience with French.

Procedure. Participants were tested in small group sessions, with each session randomly assigned to the English Subtitles, French Subtitles, or No Subtitles group. These three groups 
somewhat approximated, respectively, the three real-world situations of a film with closed captioning for the deaf, a film subtitled in a language one doesn't know (reverse subtitling, as one might see watching an American film in France), and the "typical" viewing situation of watching a film in one's own language with no subtitles. The presentation format was the same for both movie clips for each participant. After being informed that the purpose of the study was to investigate the relationship between viewing pleasure and the use of subtitles in movies, the participants saw the first of the two ten-minute movie clips on a 27 -inch screen. The order of the two clips was counterbalanced to control for practice effects. Once the first clip ended, participants completed the written recognition memory test for that clip. Immediately after completion of the test from the first clip, the second movie clip was shown, followed by the second recognition memory test and then the final demographic questionnaire. Participants were given as much time as they needed to complete the tests. The entire procedure lasted approximately 45 minutes.

\section{Results}

Preliminary analyses. Some preliminary analyses were conducted in order to rule out potential alternative explanations for findings. Performance on the filler questions on the pictorial content only was uniformly poor (less than $50 \%$ correct), and, although greater than chance $(25 \%)$, did not differ across presentation conditions. Results on these items are not considered further.

A preliminary three-way factorial ANOVA was performed on the number of correct answers, including movie and order, as well as presentation format, as independent variables. Although neither movie nor order was of theoretical interest, it was important to rule out 
systematic differences in the two clips and a simple learning effect on the second film by virtue of seeing and answering the questions on the first film. There were no significant main effects of either order or film, nor were there any interactions of these two factors. Thus we can rule out 1) an a priori advantage for one of the movie clips over the other, and 2) carryover effects giving either (a) the second film an advantage due to learning, or (b) the first film an advantage due to interference or fatigue. From here on, data from both films in both orders are aggregated.

Secondly, questions about previous viewings of movies were used as covariates to identify any differences in number of correct responses due to prior exposure. Those who had previously seen A Few Good Men performed significantly better than participants who had not, $\mathrm{F}(2,49)=14.89, \mathrm{p}<.001$, partial $\eta^{2}=.07$, but, most importantly, there was no interaction with condition. Prior exposure to See No Evil, Hear No Evil revealed no significant main effect nor interaction, suggesting that prior exposure to that film did not influence performance on the recognition-memory task. However, since differences between the two films were not of theoretical interest here, no further analyses or interpretations were made from these data and all participants were retained in the data set.

Primary analyses. A one-way ANOVA on the number of correct responses out of 41 on the items testing information in the spoken dialogue and subtitles showed a between-subjects main effect of sound, $F(2,147)=36.47, \mathrm{p}<.001$. Presentation formats containing the English Subtitles $(M=32.10$, s.d.=4.42) and French Subtitles $(M=29.86$, s.d.=5.15), which did not differ from each other by Bonferroni posthoc tests $(\mathrm{p}<.05)$, performed significantly better overall than participants who viewed the clips with No Subtitles $(M=23.16$, s.d.=6.55).

\section{Discussion}


The results of Experiment 1 revealed that type of subtitling significantly influenced recognition memory for film clips with spoken English dialogue, although not completely in the ways expected. All groups remembered at greater levels than chance (56-78\% correct, with chance being 25\%). Hypothesis 1 was partially supported, in that the English Subtitles group performed better than the No Subtitles group, although they were only marginally better than the French Subtitles group. However, Hypothesis 2 was not supported, in that the French Subtitles group did unexpectedly better than the No Subtitles group. Comparing only the English Subtitles and No Subtitles group, retention was better in the former, suggesting that the redundant English subtitles did in fact enhance memory, and there was no evidence that this verbally redundant channel served as a distractor.

The unexpectedly good performance of the French Subtitles group might be explained by the fact that French has numerous visual (orthographic) cognates to English. Many English words, especially polysyllabic words of middle- to low-frequency, are borrowed from French and look very similar in the two languages. However, these same words usually do not sound very similar. Thus, Experiment 2 extended Experiment 1 by holding English subtitles constant and varying the language in the spoken dialogue.

Experiment 2: English Subtitles with Various Languages in Spoken Dialogue

Building on the results of Experiment 1, a second experiment held the English subtitles constant and varied the language of the speech. In this study, participants viewed the same two ten-minute movie clips seen in Experiment 1, although in this case the subtitles, always in English, were held constant. The movies were presented in one of three conditions: English Sound, French Sound, or No Sound. 


\section{Hypotheses}

H3: Given that the verbally redundant condition in Experiment 1 led to the best performance, we predicted that the English Sound group should perform better than the No Sound group.

H4: If the French Sound is a distraction relative to the other groups, then memory in that condition should be worse than in the other two groups.

Method

Participants. 150 native English-speaking undergraduate students from the same population tested in Experiment 1 participated as part of their course research credit. There were 50 in each of the three groups. The English Sound group was comprised of the data from the participants from the English Subtitles group in Experiment 1, while the other two groups were new participants from the same pool. No participant in the French Sound group had any prior study of the French language.

Materials and Procedure. As in Experiment 1, participants were randomly assigned to one of three presentation formats, in this case English Sound with English Subtitles (English Sound), French Sound with English Subtitles (French Sound), or No Sound with English Subtitles (No Sound). The same recognition memory tests used in Experiment 1 were also used in Experiment 2. The experimental design and method of presentation for the movie clips and recognition memory tests was exactly the same as in Experiment 1.

Results and Discussion 
As in Experiment 1, preliminary analyses were conducted to ensure that order and movie did not systematically differ. There were no main effects or interactions of these factors. Analysis of the covariates revealed no significant influence of prior exposure to the movies.

A one-way ANOVA compared performance on the number of correct responses (out of 41) on the recognition tests for the dialogue information across conditions. The three sound conditions constituted the levels of one between-subjects independent variable. There was a main effect of sound, $\mathrm{F}(2,147)=22.99, \mathrm{p}<.001$. Pairwise Bonferroni comparisons showed that, in contrast to Experiment 1, all three groups differed significantly from each other $(\mathrm{p}<.05)$. As in Experiment 1, the redundant group with English Sound and subtitles did the best (32.10 out of 41 correct, s.d. $=4.42)$, followed by the French Sound group $(29.38$, s.d. $=5.22)$, and finally by the No Sound group (27.00, s.d.=6.04).

Thus Hypothesis 3 was supported. However, Hypothesis 4 was not, since the French Sound group actually performed better than the No Sound group, a finding which is inconsistent with the idea of the French sound being distracting. The fact that it was worse than the group with English in both modalities suggests that the redundancy of the information in the latter was useful, a finding consistent with previous research using expository materials. The fact that the French Sound group in Experiment 2 did not do as well relative to the all-English group as did the French Subtitles group in Experiment 1 may be due to the fact that French has more orthographic cognates to English than it has phonological cognates. That is, to the uninitiated, French looks a lot more like English than it sounds.

It is also noteworthy that the No Sound group in Experiment 2 performed modestly better (66\% correct) than had the No Subtitles groups in Experiment 2 (56\% correct). In other words, 
for this task, if one must have ONLY spoken dialogue or ONLY subtitles, the latter is preferable, at least in terms of recognition memory for the content. However, one question yet unanswered is that of the baseline level. Could participants get $56 \%$ correct by making good guesses from only watching the pictures? (Purely chance performance would be $25 \%$, given this four-choice format). Thus, Experiment 3 tested three final conditions where no English, and thus presumably nothing comprehensible, appeared.

\section{Experiment 3: Control Conditions with No English Channel}

A few questions remain unanswered by the first two experiments. First, we do not yet know how many questions could be answered without hearing or seeing any speech or subtitles, i.e., answerable from merely watching the pictorial content. Although the critical questions were not answered explicitly in the pictorial content, it might be possible to use that content to guess the answers. Secondly, it is possible, even if unlikely, that the speech or subtitles in a language one does not know may be minimally helpful if one's own language is not present in any format. Thus three more conditions were tested, all clearly lacking in external validity in that people would not be likely to watch a film under these conditions. However, they are needed to answer the questions above. These conditions were French Sound + French Subtitles, No Sound + French Subtitles, and No Sound + No Subtitles. The last condition should serve as a baseline for performance based only on seeing the film with no dialogue in any form, and the other two conditions tested how much above this baseline the presence of French to either the sound or subtitles or both would be. 
- H5: If incomprehensible subtitles or spoken dialogue are a distraction, memory in the No Sound + No Subtitles group should be better than in the No Sound + French Subtitles or French Sound + French subtitles groups.

\section{Method}

Experiment 3 tested 150 participants from the same participant pool as the previous two experiments. The materials and procedure used were the same as in Experiments 1 and 2, except the three groups (50 participants per group) were as follows: French Sound + French Subtitles, No Sound + French Subtitles, and No Sound + No Subtitles. No participants in either group with French subtitles had had any prior study or experience with French. Although none of their groups had much external validity, in that people are very unlikely to watch film under any of these conditions, they were necessary to establish (1) how much information people could acquire and remember merely from seeing the pictorial content, and (2) whether an unknown language in the sound and/or subtitles improved memory over this baseline level.

\section{Results and Discussion}

The mean per cent of dialogue questions answered correctly (out of 41) was between 36 and $40 \%$ correct for all three groups, with no significant differences between groups ,Means = 14.98 (s.d.=6.51), 16.44 (s.d.=6.24), and $15.66($ s.d.=6.73) out of 41 for the No Sound + No Subtitles, No Sound + French Subtitles, and the French Sound + French Subtitles groups, respectively. This may be seen as the baseline knowledge obtained from watching the pictorial content and guessing the correct answers to the recognition memory questions. Thus, there was no evidence that spoken French dialogue or subtitles either improved or interfered with memory, 
relative to the baseline of the No Sound + No Subtitles condition. On the other hand, all three groups were considerably below all conditions in Experiments 1 and 2, so participants in those studies were in fact learning the critical information from the English subtitles and/or spoken dialogue. Thus, it may be ruled out that the results in Experiments 1 and 2 came from guessing from the pictorial content. Also, there is no evidence that participants learned anything from the French sound or subtitles or even both in Experiment 3, as none of these condition was significantly better than the baseline No Sound + No Subtitles group. Thus, Hypothesis 5 was not supported. Participants were apparently neither distracted nor aided by the French sound or subtitles.

\section{General Discussion}

Taken together, several interesting findings emerge from these studies. 1) The condition with both English Sound and English Subtitles consistently produced the best memory for the dialogue content. This suggests this sort of verbal redundancy is useful and not a counterproductive distraction, supporting the findings of Moreno and Mayer (2002), who found the best retention of expository material when the words were redundantly presented in both visual and auditory modality. Although this redundant condition led to the best performance, either a familiar sound or subtitles was largely sufficient to convey the needed information, regardless of whether the other channel contained no language or an unfamiliar language. 2) There was some evidence that, given only one channel, subtitles were modestly more effective than the speech at transmitting information. The Subtitles Only group in Experiment 2 performed better than the Sound Only group in Experiment 1. It is interesting that the worst among those conditions with an English channel was the No Subtitles group in Experiment 1, the 
one which corresponds most closely to the condition under which most people actually watch movies, at least in the U.S. Most movie viewing, however, may not be engaged in primarily for maximal retention of the content but rather done largely for enjoyment. 3) The French Subtitles group in Experiment 1 performed a little better than the French Sound group in Experiment 2, consistent with the idea that participants may have been able to gain a little more from the written than from the spoken French, perhaps because of the greater orthographic than phonological similarity of French to English. This requires further research to confirm, however.

One potential explanation for the better performance by the French Subtitles group in Experiment 1, relative to the No Subtitles controls, could be that the presence of the subtitles triggered an automatic reading response. Although it may appear counterintuitive that people would try to read a language they do not understand, this finding is consistent with the findings of d'Ydewalle and de Bruycker (2007), who found that $26 \%$ of the time eye movements were on the incomprehensible subtitles when the sound was in one's native language. This explanation is also consistent with the Stroop (1935) effect, in that it is apparently difficult to completely ignore unneeded foreign subtitles. It may be that written French has enough cognates and other similarities to English that people can actually comprehend a minimal amount from it. The learning, however, was minimal at best and did not occur in conditions where there was no English channel. It would be worthwhile to replicate the study with a language with less similarity than French to English.

Another issue to consider is the congruency of presentation and test modality. In the present studies all testing was in the form of written questions, a format that might have favored subtitles over spoken dialogue. For example, in Experiment 2, participants presented with 
dialogue in a familiar language only in the subtitles performed better in recognition memory than did participants hearing familiar dialogue only in the speech (No Subtitles group in Experiment 1) or not at all (all groups in Experiment 3). These results were consistent with findings of d'Ydewalle, et al. (1987, 1991), in that recognition memory was better on written recognition tests when that information had appeared in subtitles than when it had appeared in the spoken dialogue. These results are also consistent with the principle of encoding specificity (Tulving \& Thomson, 1973), in that the encoding of written verbal information from the subtitles yielded better performance on the written recognition tests than did the same information in the spoken dialogue. Future research might test the encoding specificity explanation by using both written and oral questions and perhaps even a pictorial recognition test.

The superior memory by the condition with both English sound and English subtitles is consistent with the findings of Moreno and Mayer (2002) for the recall of verbal expository material presented in various combinations of auditory and visual format. Whereas Moreno and Mayer tested recall of the multimedia expository message, the current studies used recognition memory for verbal material in dialogue presented visually or orally in entertainment media. The similar pattern across these very different types of material (movies scenes versus expository prose) under different memory testing conditions suggests some useful generality.

Despite the fact that the present studies found that viewing a movie with native language subtitles yielded as least as good memory for content as did viewing a movie with only a native language sound, many people, especially in the U.S., are reluctant to view subtitled films. One potential reason for this is that watching movies is generally a leisure activity, where people may not desire to use particularly deep cognitive processing. Because greater focalization of attention 
and mental effort is needed to read dialogue in subtitles as opposed to listening to spoken dialogue, people viewing movies purely for entertainment may be less inclined to watch subtitled movies.

Viewing a movie with closed captions or subtitles requires greater attention to the movie overall than viewing movies in standard presentation format (i.e., Sound Only condition in Experiment 1). People viewing a movie with its sound in their own language and no subtitles may split their attention between the movie and some unrelated concurrent task, because they can obtain the gist of the movie by simply hearing the spoken information. When one is required to acquire the dialogue visually, as in the deaf reading closed captions or watching foreign movies subtitled in one's own language, both gaze and visual attention must remain continually focused on the screen to comprehend the needed verbal information, thus promoting, even if sometimes reluctantly, a deeper level of processing (Craik \& Lockhart, 1972).

Several directions may be identified for future research. Different foreign languages with less similarity to English could be studied. With such unrelated languages, it would be very unlikely that participants could guess their meaning, as they might have done with French in the present studies. It would also be interesting to test languages written in a different script altogether. If there is a sort of Stroop-like effect to attempt to read unfamiliar languages, this effort should be markedly less successful with non-Indo-European languages written in the Latin alphabet (e.g., Finnish, Hungarian, Indonesian, or Vietnamese) and a total failure for languages written in an unfamiliar script (e.g., Chinese, Hindi, Thai, or Korean), none of which were available for the present movies. Any effort made to try to read these foreign scripts might well 
be cognitively very costly, in that it would greatly distract viewers from the comprehensible sound and pictorial content.

Another useful extension suggested by the French conditions would be to examine the role of intermediate language fluency in memory for information from sound and subtitles. Although participants in the current studies were screened to exclude those who had studied French, some had studied other related languages, most often Spanish, and may have used that knowledge to recognize some of the words. Testing participants with a wide range of intermediate fluency in Spanish, for example, could examine how much language skill is necessary in order to begin to help comprehend subtitles or spoken dialogue in that language.

\section{Author Notes}

Richard Jackson Harris is Professor of Psychology at Kansas State University. His current research interests are memory for language and mass communication, bilingualism, and autobiographical memory. These data are based on the Master's Thesis of Michael Hinkin. 


\section{References}

Bergen, L., Grimes, T., \& Potter, D. (2005). How attention partitions itself during simultaneous message presentations. Human Communication Research, 31, 311--336.

Craik, F. I. M., \& Lockhart, R. S. (1972). Levels of processing: A framework for memory research. Journal of Verbal Learning and Verbal Behavior, 11, 671--684.

De Bruycker, W., \& d'Ydewalle, G. (2003). Reading native and foreign language television subtitles in children and adults. In J. Hyona, R. Radach, \& H. Deubel (Eds.), The mind's eye” Cognitive and applied aspects of eye movement research. (pp. 671--684). Amsterdam: Elsevier.

De Linde, Z., \& Kay, N. (1999). Processing subtitles and film images: Hearing vs. deaf viewers. The Translator, 5, 45--60/

Dias-Cintas, J., \& Remael, A. (2007). Audiovisual translation: Subtitling. Manchester UK: St. Jerome Publishing.

d'Ydewalle, G., \& de Bruycker, W. (2007). Eye movements of children and adults while reading television subtitles. European Psychologist, 12 (3), 196--205.

d'Ydewalle, G., Praet, C., Verfaillie, K., \& van Rensbergen, J. (1991). Watching subtitled television: Automatic reading behavior. Communication Research, 18 (5), 650--666.

d'Ydewalle, G., \& Van de Poel, M. (1999). Incidental foreign-language acquisition by children watching subtitled television programs. Journal of Psycholinguistic Research, 28, 227-244. 
d'Ydewalle, G., Van Rensbergen, J., \& Pollet, J. (1987). Reading a message when the same message is available auditorily in another language: The case of subtitling. In J.K. O’Regan \& A. Levy-Schoen (Eds.), Eye movements: From physiology to cognition. (Pp. 313--321.) Amsterdam: North-Holland.

Germeys, F., \& d'Ydewalle, G. (2007). The psychology of film: Perceiving beyond the cut Psychological Research, 71, 458--466.

Harris, R. J., Cady, E. T., \& Tran, T. Q. (2006). Comprehension and memory. In J. Bryant and P. Vorderer (Eds.), Psychology of entertainment. (pp. 71--84). Mahwah NJ: Lawrence Erlbaum Associates.

Harris, R. J., Werth, A. J., Bures, K. E., \& Bartel, C. M. (2008). Social movie quoting: What, why, and how? Ciencias psicologicas, 2 (1), 35--45.

Ivarsson, J., \& Carroll, M. (1998) Subtitling. Simrishamn. Sweden: Transedit.

Kalyuga, S., Chandler, P., \& Sweller, J. (1999). Managing split-attention and redundancy in multimedia learning. Applied Cognitive Psychology, 13, 351--371.

Koolstra, C. M., Peeters, A. L., \& Spinhof, H. (2002). The pros and cons of dubbing and subtitling. European Journal of Communication, 17, 325--354.

Kothari, B. (1998). Film songs as continuing education: Same language subtitling for literacy. Economic and Political Weekly, 33, 2507--2510. 
Kothari, B. (2000). Same language subtitling on Indian television: Harnessing the power of popular culture for literacy. In K. Wilkins (Ed.)., Redeveloping communication for social change: Theory, practice and power. (pp. 135--146). New York: Rowman and Littlefield.

Kothari, B. Pandey, A., \& Chudgar, A. R. (2004). Reading out of the "idiot box": Same-language subtitling on television in India. Information Technologies and International Development, 2(1), 23--44.

Kuppens, A. H. (2010). Incidental foreign language acquisition from media exposure. Learning, Media and Technology, 35, 65--85.

Lang, A. (1995). Defining audio/visual redundancy from a limited-capacity information processing perspective. Communication Research, 22(1), 86--115.

Lang, A. (2000).The limited capacity model of mediated message processing, Journal of Communication, 50, 46--70.

Lavaur, J.-M., \& Bairstow, D. (2011). Languages on the screen: Is film comprehension related to the viewers' fluency level and to the language in the subtitles? International journal of Psychology, 46, 455--462.

Lindow, S., Fuchs, H. M., Furstenberg, A., Kleber, J., Schweppe, J., \& Rummer, R. (2010) On the robustness of the modality effect: Attempting to replicate a basic finding. Zeitschrift fur Padagogische Psychologie, 24, 231--243.

Martin, R. C., Wogalter, M. S., \& Forland, J. G. (1988). Reading comprehension in the presence of unattended speech. Journal of Memory and Language, 27, 382--398. 
Mayer, R. E. (1997). Multimedia learning: Are we asking the right questions? Educational Psychology, 32 (1) , 1--19.

Mayer, R. E. (2005). Cognitive theory of multimedia learning. In R.E. Mayer (Ed.) The Cambridge handbook of multimedia learning.. (pp. 31--48) New York: Cambridge University Press.

Mayer, R. E. (2009), Multimedia learning. ( $2^{\text {nd }}$ ed.) New York: Cambridge University Press.

Mayer, R. E., \& Moreno, R. (1998). A split-attention effect in multimedia learning: Evidence for dual processing systems in working memory. Journal of Educational Psychology, 90 (2), 312--320.

Moreno, R., \& Mayer, R. E. (2002). Verbal redundancy in multimedia learning: When reading helps listening. Journal of Educational Psychology, 94 (1), 156--163.

Pavlovic, N. (2004). Addressing power and solidarity in TV subtitling. Across Language and Cultures, 5(2), 211--232.

Perego, E., del Missier, F., Porta, M., \& Mosconi, M. (2010). The cognitive effectiveness of subtitle processing. Media Psychology, 13, 243--272.

Rummer, R., Schweppe, J., Furstenberg, A., Scheiter, K., \& Zindler, A. (2011). The perceptual basis of the modality effect in multimedia learning. Journal of Experimental Psychology: Applied, 17, 159--173. 
Rummer, R., Schweppe, J., Furstenberg, A., Seufert, T., \& Brunken, R. (2010). Working memory interference during processing texts and pictures: Implications for the explanation of the modality effect. Applied Cognitive Psychology, 24, 164--176.

Schilperoord, J., de Groot, V., \& van Son, N. (2005). Nonverbatim captioning in Dutch television programs: A text linguistic approach. Journal of Deaf Studies and Deaf Education, 10(4), 402--416.

Schuler, A. Scheiter, K., \& Schmidt-Weigand, F. (2010). Boundary conditions and constraints of the modality effect. Zeitschrift fur Padagogische Psychologie, 24, 211--220.

Stroop, J. R. (1935). Studies of interference in serial verbal reactions. Journal of Experimental Psychology, 18, 643--662.

Sweller, J. (2005). Implications of cognitive load theory for multimedia learning. In R.E. Mayer (Ed.) The Cambridge handbook of multimedia learning.. (pp. 19--30) New York: Cambridge University Press.

Tulving, E. \& Thomson, D.M. (1973). Encoding specificity and retrieval processes in episodic memory. Psychological Review, 80(5), 352--373.

Van Lommel, S., Laenen, A., \& d'Ydewalle, G. (2006). Foreign-grammar acquisition while watching subtitled television programmes. British Journal of Educational Psychology, $76,243--258$.

Zhou, S. (2004). Effects of visual intensity and audiovisual redundancy in bad news. Media 
Psychology, 6, 237-256. 